\title{
CORRIGENDUM
}

\section{Corrigendum to 'Gender-specific presentations for asthma, allergic rhinitis and eczema in primary care' [Prim Care Resp J 2007;16(1):28-35]}

\section{Mustafa Osman, Anna L Hansell, Colin R Simpson, Jennifer Hollowell, Peter J Helms}

The authors regret that an error occurred on page 30, caption to Figure 2:

The caption 'Patient consultation rates for asthma by single year of age for ages...'

should read:

'Patient consultation rates for allergic rhinitis by single year of age for ages...'

Corresponding author. Dr M Osman, Consultant Paediatrician, 34 Cairnfield Place, Aberdeen. AB15 5NA

Tel.: +44(0)1224 635151; fax.: +44(0) 1224 27204. E-mail address: m.osman@abdn.ac.uk

DOI of original article:10.3132/pcrj.2007.00006 